\title{
Vitamin D Deficiency, the Volume of the Problem in the United Arab Emirates. A Cohort from the Middle East
}

\author{
Elamin IE. Abdelgadir*, Fouzia Rashid, Alaaeldin MK Basheir", Fatheya Alawadi”, Hamad Al Suwidi, Ahmed Eltinay \\ Endocrine department, Dubai Hospital, Dubai, United Arab Emirates \\ ${ }^{\#}$ These authors equally contributed
}

\begin{abstract}
Received: March 02, 2016; Accepted: April 06, 2016; Published: April 17, 2016
*Corresponding author: Elamin IE. Abdelgadir, Endocrine department, Dubai Hospital, Dubai, United Arab Emirates, Tel: +00971 553370971; Email: alaminibrahim@hotmail.com
\end{abstract}

Keywords: Vitamin D; Deficiency; United Arab Emirates; UAE, Osteoporosis

\section{Introduction}

During the last two or three decades, Vitamin d deficiency has become an extremely hot scientific area of research. Given the background of vitamin D synthesis, and since its human production is solely based on the sun exposure. We expect Vitamin D deficiency to be an un-noticeable clinical burden in the Middle East. Sunny days in the Middle East run through, almost, the whole year. Al Anouti et al. unveiled an important clinical observation when they examined the vitamin D level in random sample of university students in Al Ain city in the United Arab Emirates (UAE). The average Vitamin D level during summer was $20.9+/-14.9$ and $27.3+/-15.7 \mathrm{ng} / \mathrm{mL}$ in females and males respectively. While winter vitamin $D$ levels in females found to be $31.3+/-12.3 \mathrm{ng} / \mathrm{mL}$. The researches thought this summer high rates could be due to sun light avoidance during the hot summer in this region [1].

Vitamin D deficiency in UAE, and based on multiple clinical sets of data, has been proven to be a major health issue. A study from Dubai, the second largest emirate (state) in the United Arab Emirates (UAE), showed prevalence of vitamin D levels < 30ng/ $\mathrm{ml}$ (deficiency and insufficiency) of $81 \%$ out of 2836 individuals who attended the biggest governmental hospital in Dubai [2].

Different studies have shown similar indices of the unexpected high prevalence of vitamin D deficiency in the Middle East region [3-5]. Most of the researchers attributed this to the avoidance of sun exposure plus or minus inappropriate dietary habits [6-8]. Nonetheless, this problem is not only confined to the adult population. A study conducted among the adolescents in Al Ain city (UAE), showed prevalence of vitamin $\mathrm{D}<30 \mathrm{ng} / \mathrm{ml}$ of $65 \%$, the lower percentage could be explained by longer sun exposure at school age [9].

In this study, we are looking into the depth of the problem in Dubai; we evaluated all the vitamin D tests results in the Dubai governmental hospitals and clinics (Dubai health Authority) over the period of 2007 to 2015 .

Dubai Health Authority (DHA) is the only governmental group of hospitals and primary health care centers. Out of the 2.2 millions Dubai citizens, all Emirati nationals receive free treatment there, so they usually prefer treatment within the DHA facilities. All those who work for the government and the government-allied companies get their treatment for free. Moreover, DHA receives the majority of the daily emergencies being the main tertiary hubs in the city. This makes the sample reflecting, to a large extent, the true prevalence of any disease, when we are assessing it retrospectively.

\section{Patients and Methods}

\section{Objectives}

Primarily we wished to assess the prevalence of vitamin D deficiency in the population of Dubai. Secondarily, we aimed to evaluate further the specific prevalence in males and females separately, prevalence at different ages and in ethnic groups.

\section{Study design and population}

This is a retrospective study that has been conducted in Dubai Health Authority, Dubai, United Arab Emirates; the aim of the study is to assess degree of vitamin D deficiency and insufficiency in the population of Dubai.

We included all patients aged 3-100 years who attended any of Dubai health authority clinics in the period between Jan 2007 till May 2015. We collected the patients who had their first vitamin D level before starting vitamin D supplementation.

Our data collection sheet included patients' age, gender, nationality, vitamin D level, and creatinine.

\section{Biochemical analysis}

All vitamin D measurements in Dubai Health Authority are performed locally at a single reference biochemistry laboratory. A radioimmunoassay method (Diasource, Louvain-la-Neuve, Belgium) was used with standard internal and external quality assurance practices. 


\section{Definition}

Vitamin D deficiency was defined according to our local laboratory values as a $25(\mathrm{OH}) \mathrm{D}$ below $10 \mathrm{ng} / \mathrm{ml}$, insufficiency as a $25(\mathrm{OH}) \mathrm{D}$ of $11-29 \mathrm{ng} / \mathrm{ml}$ and sufficient when $25(\mathrm{OH}) \mathrm{D}$ is $30-100 \mathrm{ng} / \mathrm{ml}$.

\section{Data analysis}

Data analysis was performed on SPSS software 16.0. In all analyses, a $p$-value $<0.05$ was considered significant and $P<0.001$ was considered highly significant. Quantitative variables were described as mean; Standard Deviation (SD) and range, qualitative were described as variables as number and percentage.

We have used the Chi-square test to compare qualitative variables between groups.

\section{Results}

We have assessed 112,499 patients. $64.5 \%$ of the patients (n $=72,610)$ were females, while $35.5 \%$ of the patients were males ( $\mathrm{n}=39,889$ ). $77.2 \%$ were Arabic inhabitants $(\mathrm{n}=88,755)$, while $22.8 \%$ were non-Arabs $(n=23,744)$, Emirati were $76.3 \%$ of the total population.

$29.5 \%$ of the patients $(\mathrm{n}=32,968)$ had vitamin D levels < $10 \mathrm{ng} / \mathrm{ml}$. vitamin D of $10-30 \mathrm{ng} / \mathrm{ml}$ was found in $63.3 \%$ of the patients $(\mathrm{n}=70653)$ (Table 1 ; figure 1$)$.

Out of the males patients 20.8\% $(\mathrm{n}=8242)$ and $72.8 \%(\mathrm{n}=$ 28837) had vitamin D level of $<10$ and $10-30 \mathrm{ng} / \mathrm{ml}$, respectively. While the females cohort $34.3 \%(n=24726)$ had vitamin D level $<10 \mathrm{ng} / \mathrm{ml}$, and 58.1\% $(\mathrm{n}=41816)$ had vitamin D level 10-30ng/ $\mathrm{ml}$ with high statically significant difference $(p=0.00)$. Only 31 males $(0.1 \%)$ and $125(0.2 \%)$ females had vitamin D level > $100 \mathrm{ng} / \mathrm{ml}$ (figure 2).

When compared vitamin D levels in Arabs and other nationalities we found that vitamin $\mathrm{D}<10 \mathrm{ng} / \mathrm{ml}$ was seen in $31.4 \%$ of Arabs ( $n=29865)$ vs. $21.9 \%(n=3093)$ from other nationalities, again $10-30 \mathrm{ng} / \mathrm{ml}(\mathrm{n}=60240)$ vs. $73.7 \%(\mathrm{n}=$ 10394), and 30-75 in 5.1\% ( $\mathrm{n}=4801)$ of Arabs and $4.4 \%(\mathrm{n}=$ 618) of other nationalities $p=0.00$. Upon further analysis of the patients' nationalities; vitamin D deficiency was more prevalent in the Emiratis cohort than all the expatriates $32 \%$ vs. $24 \%$, respectively with a p value of 0.001 (Table 2 ).

Levels of vitamin D at different age groups are shown in (Table 3). Interestingly, the middle-aged group of patients had the highest prevalence of vitamin D deficiency, where the younger patients (13-18 years) had 48.4\% $(n=3794)$ and $49.9 \%$ (3906) levels of vitamin D of $<10$ and $10-30 \mathrm{ng} / \mathrm{ml}$, respectively with a $\mathrm{p}$ value of 0.000 (Table 3 ).

\section{Discussion}

To our best knowledge there is no any published work on vitamin D with a number of patients similar to this data. Assessing 112,499 individual attending all the government hospitals in Dubai emirate between 2007 and 2015 makes it a very valuable and objective tool to assess the depth of the problem nationally,
Table 1: Distribution of the studied group according to vitamin D levels. This table shows majority of patients having Vitamin D insufficiency or deficiency.

\begin{tabular}{|l|l|l|}
\hline Vitamin D level & Number of patients & \% \\
\hline$<\mathbf{1 0}$ & 32968 & $29.5 \%$ \\
\hline $\mathbf{1 0 - 3 0}$ & 70653 & $63.3 \%$ \\
\hline $\mathbf{3 0 - 7 5}$ & 7557 & $6.8 \%$ \\
\hline $\mathbf{7 5 - 1 0 0}$ & 300 & $0.3 \%$ \\
\hline $\mathbf{> 1 0 0}$ & 159 & $0.1 \%$ \\
\hline
\end{tabular}

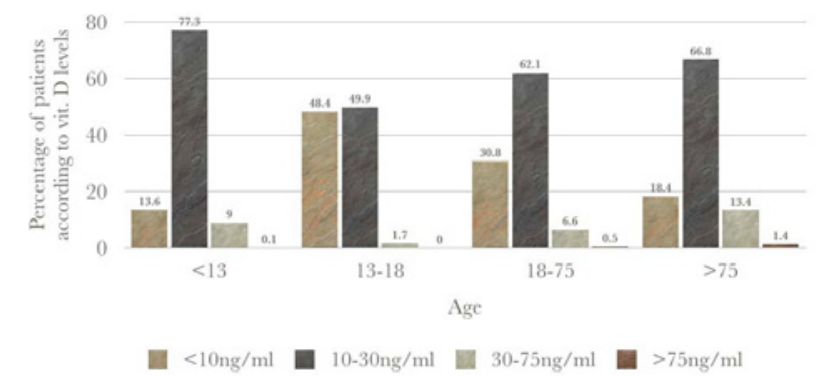

Figure 1: This graph shows distribution of the vitamin D deficiency and insufficiency according to the age groups.

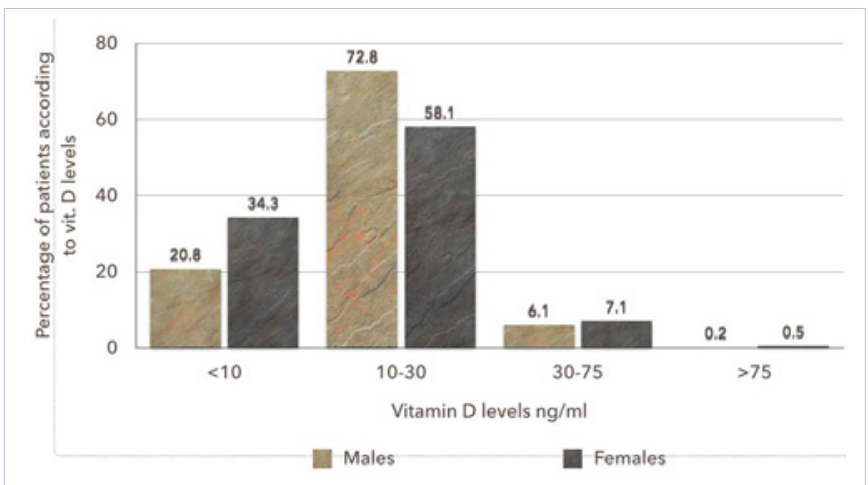

Figure 2: This graph shows the gender difference in the vitamin D deficiency and insufficiency.

and or regionally. Dubai population is just over 2.2 million people. We are assessing almost $4 \%$ of the total population, keeping in mind there are number of national patients attend those hospitals coming from other emirates.

Hypovitaminosis D is a pandemic problem and our findings of low vitamin D level in this large sample of residents of Dubai, United Arab Emirates (UAE), also emphasize the importance to address this problem effectively.

UAE in spite being a sunny subtropical country, with maximum span of summer in all seasons, is now widely known to have comparable vitamin D deficiency as other part of globe $[10,11]$.

The composite prevalence of vitamin D deficiency and insufficiency in patients attending Dubai health authority was 
Table 2: Comparison between vitamin D levels versus nationality.

\begin{tabular}{|c|c|c|c|c|}
\hline \multirow{2}{*}{ Vitamin D level } & \multicolumn{2}{|l|}{ Nationality } & \multirow{2}{*}{$\mathrm{X}^{2}$} & \multirow{2}{*}{$\mathbf{P}$} \\
\hline & UAE & others & & \\
\hline$<10$ & $27028(32 \%)$ & $6263(24.3 \%)$ & \multirow{5}{*}{6} & \multirow{5}{*}{ P $0.0001 \mathrm{HS}$} \\
\hline $10-30$ & $53212(62.9 \%)$ & $18263(71 \%)$ & & \\
\hline $30-75$ & 4292 (5.1\%) & $1199(4.7 \%)$ & & \\
\hline $75-100$ & $5(0.0 \%)$ & 0 & & \\
\hline \multirow[t]{3}{*}{$>100$} & $57(0.1 \%)$ & $4(0.0 \%)$ & & \\
\hline & \multicolumn{2}{|l|}{ Nationality } & & \\
\hline & Arabs & Others & & \\
\hline$<10$ & 29865 (31.4\%) & 3093 (21.9\%) & \multirow{5}{*}{5.8} & \multirow{5}{*}{$0.0001 \mathrm{HS}$} \\
\hline $10-30$ & $60240(61.3 \%)$ & $10394(73.7 \%)$ & & \\
\hline $30-75$ & $4801(5.1 \%)$ & 5.8 & & \\
\hline $75-100$ & $5(0.0 \%)$ & 0 & & \\
\hline$>100$ & $58(0.1 \%)$ & $3(0.0 \%)$ & & \\
\hline
\end{tabular}

This table shows that UAE had higher vitamin D deficiency rates compared to other nationalities with statistically significant difference by using chisquare test. While, overall Arabs had higher prevalence of vitamin D compared to other nationalities with statistically significant difference by using chi-square test.

Table 3: Relation between vitamin D level and different age groups.

\begin{tabular}{|c|c|c|c|c|c|c|}
\hline \multirow{2}{*}{ Vitamin D level } & \multicolumn{4}{|l|}{ Age } & \multirow{2}{*}{$\mathbf{X}^{2}$} & \multirow{2}{*}{$\mathbf{P}$} \\
\hline & $<13$ & $13-18$ & $18-75$ & $>75$ & & \\
\hline$<10$ & $1938(13 \%)$ & $13-18$ & $26673(30.8 \%)$ & $563(18.4 \%)$ & \multirow{5}{*}{3.7} & \multirow{5}{*}{$0.000 \mathrm{HS}$} \\
\hline $10-30$ & $11033(77.3 \%)$ & 3794 (48.4\%) & $53669(62.1 \%)$ & 2044 (66.8\%) & & \\
\hline $30-75$ & $1281(9 \%)$ & 3906 (49.9\%) & $5736(6.6 \%)$ & $410(13.4 \%)$ & & \\
\hline 75-100 & 17 (0.1\%) & 130 (1.7\%) & $251(0.3 \%)$ & $30(1 \%)$ & & \\
\hline$>100$ & $7(0.0 \%)$ & $2(0.0 \%)$ & $137(0.2 \%)$ & $12(0.4 \%)$ & & \\
\hline
\end{tabular}

This table shows that younger age group less than 13 had lower vitamin D level compared to older age group with statistically significant difference by using chi-square test.

found to be surprisingly high (92.7\%) and this is a confirmatory replication of different studies conducted in this region, Middle East. A study conducted by the same group of this paper on the patients attending a general hospital in Dubai showed prevalence of $93.3 \%[2]$.

We found significant number of both males and females with vitamin D deficiency however percentage of female who are deficient is more than males. This observation has been seen before [12], and contributed to physiologic stress like pregnancy, lactation, low physical activity, and inadequate dietary vitamin D consumption $[13,14]$. Traditionally females here are not much exposed to outdoors and though in local UAE population both males and female usually covers whole body and limbs, but in general, Arab females observe covering of arms and face also [15,16], which can contribute to more pronounced vitamin D deficiency in them [17]. Skin exposure to sunlight is of prime importance as vitamin D is synthesize from a precursor 7-dehydrocholesterol naturally present in the skin ,which subsequently converted to active vitamin D after 2 step hydroxylation in liver and kidney [18].

This is one of the reasons that elderly people usually have low vitamin D level as skin concentration of 7- dehydrocholesterol gradually declined with growing age. A 70-year-old male will have $25 \%$ less of this vitamin D precursor than a young adult [19].

Our findings that young adults have equal chances of vitamin D insufficiency like middle aged individuals replicating the results observed by Tangpricha vin, et al. (2002)[20]. Indeed our observation that adolescent residing in Dubai have much higher percentage of vitamin D deficiency than expected, has been seen before by a group of investigators in Al-Ain ,United Arab Emirate, they found majority of young Emirati girls attending public school, aged between 11-18year, were deficient in Vitamin D [21].

Our findings of low vitamin D level in young healthy males are also seen in a study done in Saudi Arabia: Riyadh region where 
young males aged between 18-23 years were found to have vitamin D deficiency [22].

This problem is not limited to middle East region it has been identified in many previous studies in other parts of world as well $[23,24]$ these observations dictate the need to address this issue of low vitamin D level in these young adolescent from beginning to anticipate adverse bone health outcome from early age.

Our study despite having observed first ever checked vitamin D level in a huge number of individuals in our data base, have many limitations, being a retrospective study, we cannot identify the associated co morbid condition like malabsorption, obesity [25] dietary habits [26], physical activities, seasonal variation [27] and history of vitamin D supplement, which all may have some influence on level of vitamin D compare to healthy individuals. But at least the yield of our observation carries enough strength to confirm the burden of this problem in residents of Dubai and encouragement of more sun exposure and life style modification. This study may also in future be able to answer the optimal level of vitamin $\mathrm{D}$ that has been a topic of debate since long.

\section{Conclusion}

Vitamin D deficiency is a very common medical problem in Dubai, the over all prevalence was $29.5 \%$, while $63.6 \%$ had levels below 30ng/ $\mathrm{ml} 92.8 \%$ out of over 112,000 patients. Male are substantially affected more than females. There is statistically significant difference between Emiratis and the expatriates, with higher rates in emirates population. Those results need to be taken very seriously in terms of raising the awareness about the disease and the need for further studies about any associated health consequences, which may arise if left untreated. Nonetheless, having the prevalence of over $90 \%$ could raise a question whether the international cutoff points fit our region's population or not?

\section{References}

1. Al Anouti F, Thomas J, Abdel-Wareth L, Rajah J, Grant WB, Haq A. Vitamin D deficiency and sun avoidance among university students at Abu Dhabi, United Arab Emirates. Dermatoendocrinology. 2011;3(4):235-9. doi: 10.4161/derm.3.4.16881.

2. Abdelgadir E, Bashier A, Kathamuthu R, Bashiri, S, Alawadi F. Vitamin D Deficiency and Insufficiency in Patients Attending a General Hospital in Dubai, United Arab Emirates. Ibnosina Journal of Medicine and Biomedical Sciences. 2013;6(2):81.

3. Mahdy SM, Al-Emadi SA, Khanjar IA, Hammoudeh MM, Sarakbi HA Siam A, et al. Vitamin D status in health care professionals in Qatar. Saudi Med J. 2010;31(1):74-7.

4. Dawodu A, Absood G, Patel M, Agarwal M, Ezimokhai M, Abdulrazzaq $\mathrm{Y}$, et al. Biosocial factors affecting vitamin D status of women of childbearing age in the United Arab Emirates. J Biosoc Sci. 1998;30(4):431-7.

5. Moussavi M, Heidarpour R, Aminorroaya A, Pournaghshband Z, Amini M. Prevalence of Vitamin D

6. Webb AR, Kline L, Holick MF. Influence of season and latitude on cutaneous synthesis of vitamin D3: exposure to winter sun in Boston and Edmonton will not promote vitamin D3 synthesis in human skin. J Clin Endocrinol Metab 1988;67(2):373-8.
7. Need AG, Morris HA, Horowitz M, Nordin C. Effects of skin thickness, age, body fat, and sun light on serum 25 -hydroxy vitamin D. Am J Clin Nutr. 1993;58(6):882-5.

8. Pfieifer M, Begerow B, Minne HW, Abrams C, Nachtigall D, Hansen C. Effects of vitamin $D$ and Calcium supplementation on body sway and secondary hyperparathyroidism in elderly women. J Bone Miner Res. 2000;15(6):1113-8.

9. Muhairi SJ, Mehairi AE, Khouri AA, Naqbi MM, Maskari FA, Al Kaabi J, et al. Vitamin D deficiency among healthy adolescents in Al Ain, United Arab Emirates. BMC public health. 2013;13:33. doi: 10.1186/14712458-13-33.

10. Kumar J, Muntner P, Kaskel FJ, Hailpern SM, Melamed ML. Prevalence and associations of 25-hydroxyvitamin D deficiency in US children: NHANES 2001-2004. Pediatrics. 2009;124(3): e362-70. doi: 10.1542/ peds.2009-0051.

11. Muhairi SJ, Mehairi AE, Khouri AA, Naqbi MM, Maskari FA, Al Kaabi J, et al. Vitamin D deficiency among healthy adolescents in Al Ain, United Arab Emirates. BMC Public Health. 2013;13:33. doi: 10.1186/14712458-13-33.

12. Gannage-Yared MH, Chemali R, Yaacoub N, Halaby G. Hypovitaminosis $\mathrm{D}$ in a sunny country: relation to lifestyle and bone markers. J Bone Miner Res. 2000;15(9):1856-62.

13. Laleye LC, Kerkadi AH, Wasesa AA, Rao M V, Aboubacar A. Assessment of vitamin D and vitamin A intake by female students at the United Arab Emirates University based on self-reported dietary and selected fortified food consumption. Int J Food Sci Nutr. 2011;62(4):370-6.

14. Nesby-O'Dell S, Scanlon KS, Cogswell ME, Gillespie C, Hollis BW, Looker AC, et al. Hypovitaminosis D prevalence and determinants among African American and white women of reproductive age: third National Health and Nutrition Examination Survey, 1988-1994. Am J Clin Nutr. 2002;76(1):187-92.

15. Tsur A, Metzger M, Dresner-Pollak R. Effect of different dress style on vitamin D level in healthy young Orthodox and ultra-Orthodox students in Israel. Osteoporos Int. 2011;22(11):2895-8.

16. Hatun S, Islam O, Cizmecioglu F, Kara B, Babaoglu K, Berk F, et al. Subclinical vitamin D deficiency is increased in adolescent girls who wear concealing clothing. J Nutr. 2005;135(2):218-22.

17. Mallah EM, Hamad MF, Elmanaseer MA, Qinna NA, Idkaidek NM, Arafat TA, et al. Plasma concentrations of 25-hydroxyvitamin D among Jordanians: Effect of biological and habitual factors on vitamin D status. BMC Clin Pathol. 2011;11:8.

18. Holick MF. Vitamin D deficiency. N Engl J Med. 2007;357(3):266-81.

19.29. Holick MF, Matsuoka LY, Wortsman J. Age, vitamin D, and solar ultraviolet. Lancet. 1989;2(8671):1104-5.

20. Tangpricha V, Pearce EN, Chen TC, Holick MF. Vitamin D insufficiency among free-living healthy young adults. Am J Med. 2002;112(8):65962.

21. Narchi H, Kochiyil J, Al Hamad S, Yasin J, Laleye L, Al Dhaheri A. Hypovitaminosis D in adolescent females--an analytical cohort study in the United Arab Emirates. Paediatr Int Child Health. 2015;35(1):3643.

22. Sedrani SH. Low 25-hydroxyvitamin D and normal serum calcium concentrations in Saudi Arabia: Riyadh region. Ann Nutr Metab. 1984;28(3):181-5.

23.Vierucci F, Del Pistoia M, Fanos M, Erba P, Saggese G. Prevalence 
of hypovitaminosis D and predictors of vitamin D status in Italian healthy adolescents. Ital J Pediatr. 2014;40:54.

24. Gordon CM, DePeter KC, Feldman HA, Grace E, Emans SJ. Prevalence of vitamin D deficiency among healthy adolescents. Arch Pediatr Adolesc Med. 2004;158(6):531-7.

25. Wortsman J, Matsuoka LY, Chen TC, Lu Z, Holick MF. Decreased bioavailability of vitamin D in obesity. Am J Clin Nutr. 2000;72(3):6903.
26. Fraser DR. Vitamin D-deficiency in Asia. J Steroid Biochem Mol Biol. 2004;89-90(1-5):491-5.

27. Szabó B, Tabák ÁG, Toldy E, Szekeres L, Szili B, Bakos B, et al. The role of serum total and free 25-hydroxyvitamin D and PTH values in defining vitamin $D$ status at the end of winter: a representative survey. J Bone Miner Metab. 2015. 